\title{
INVESTIGAÇÃO COMO INSTRUMENTO DA FORMAÇÃO PROFISSIONAL DE DOCENTES
}

\author{
Maria do Céu ROLDÃO \\ CEDH, Centro de Estudos para o Desenvolvimento Humano \\ Universidade Católica Portuguesa- UCP \\ Lisboa, Portugal \\ mrceuroldao@gmail.com \\ ORCID: https://orcid.org/0000-0002-0151-7760
}

\begin{abstract}
RESUMO: A temática que se aborda neste texto suporta-se na eleição de alguns eixos que ao longo do tempo foram sendo trabalhados de forma sistemática na pesquisa relativa ao campo, com referência particular aos contributos de Marli André (1985, 2010, 2010 a), e à abertura na ANPED ${ }^{1}$ de um espaço de discussão que partilhei. Assim, o enfoque desta análise dirige-se aos pontos centrais desse debate ao longo dos últimos 20 anos: (1) a delimitação do campo da formação de professores, (2) a natureza do conhecimento profissional docente, (3) a dialética teoria-prática nos processos formativos, (4) a distância entre universidades e escolas neste processo e (5) o lugar da pesquisa como eixo agregador de uma reconceptualização do profissional docente.
\end{abstract}

PALAVRAS-CHAVE: Pesquisa em formação de professores. Tributo a Marli André. Conhecimento profissional docente.

\section{RESEARCH AS AN INSTRUMENT OF PROFESSIONAL TEACHER EDUCATIONAL}

\begin{abstract}
The theme addressed in this text is supported by the election of some axes that over time have been systematically worked on in research related to the field, with particular reference to the contributions of Marli André (1985, 2010, 2010a), and to the opening at ANPED of a space for discussion that I shared. Thus, the focus of this analysis addresses the central points of this debate over the last 20 years: (1) the delimitation of the field of teacher education, (2) the nature of professional teaching knowledge, (3) the theory- practice in training processes, (4) the distance between universities and schools in this process and (5) the place of research as the aggregating axis of a reconceptualization of the teaching professional.
\end{abstract}

KEYWORDS: Research in teacher education. Tribute to Marli André. Teacher professional knowledge. 


\section{LA INVESTIGACIÓN COMO INSTRUMENTO DE PROFESIONAL DOCENTE EDUCATIVO}

RESUMEN: La temática abordada en este texto se sustenta en la elección de algunos ejes que a lo largo del tiempo se han trabajado sistemáticamente en investigaciones relacionadas con el campo, con especial referencia a los aportes de Marli André (1985, 2010, 2010a), y a la apertura en ANPED de un espacio de discusión que compartí. Así, el foco de este análisis aborda los puntos centrales de este debate durante los últimos 20 años: (1) la delimitación del campo de la formación del profesorado, (2) la naturaleza del conocimiento docente profesional, (3) la teoría-práctica en procesos de formación, (4) la distancia entre universidades y escuelas en este proceso y (5) el lugar de la investigación como eje agregador de una reconceptualización del profesional docente.

PALABRAS CLAVE: Investigación sobre la formación del profesorado. Homenaje a Marli André. Conocimientos profesionales docentes. 


\section{Introdução}

A Marli André

In memoriam

Há quase 30 anos, participei numa Mesa Redonda sobre formação de professores num congresso da AFIRSE, realizado na Universidade de Lisboa, e coube-me, além de apresentar a minha comunicação, moderar o debate. Duas colegas brasileiras integravam a Mesa, e gerou-se uma discussão muito viva e, no final, as três comentámos quão frustrantes são estes eventos científicos em que nos empenhamos, pela escassez de tempo para discutir ideias de facto, mais se assemelhando a um enorme mercado de apresentação de produtos, sem prejuízo da qualidade que tenham. Ficámos, pois, as três no que em Portugal chamamos uma alegre "cavaqueira" e descobrimos, com mútuo prazer, um sem número de afinidades nas situações dos nossos dois países, e uma proximidade ainda mais evidente nos pontos de análise em que as três nos posicionávamos. Uma delas é a minha queridíssima companheira de muitos trabalhos e escritas Laurizete Ferragut. A outra era Marli André.

Foi o início de uma profunda amizade e de uma colaboração regular que me liga a ambas, no caso de Marli tragicamente interrompida no início deste ano de 2021. Este texto, que lhe dedico, procura carregar em si muito do que aprendi com ela, textos que produzi a pedido dela no Gt8 da ANPEd em que me honrou com seus frequentes pedidos de colaboração, ideias - muitíssimas - que aprofundámos juntas, debatemos e ampliámos. É por isso mais do que uma autoria individual, uma tessitura de ideias, ditas ou publicadas, que sei que em boa parte lhe devo. O meu obrigada. Até sempre.

\section{Formação de professores - a delimitação de um campo}

A delimitação do campo de estudo da Formação de Professores foi objeto de um Seminário organizado pelo Gt8 (Grupo de trabalho da Formação de Professores) da ANPEd, em São Paulo, em julho de 2006, em que tive o prazer de participar. Do texto que então sintetizou as minhas concepções sobre os limites do campo (Roldão, 2007) retomo, como enquadramento prévio da meta-análise de revisões de pesquisa portuguesa sobre Formação de Professores desenvolvida nesse texto, alguns pontos essenciais:

a) a coexistência de duas linhas de análise predominantes na investigação sobre o tema - uma mais focada, centrada na natureza da atividade, na profissionalidade docente em si mesma como referente do campo da formação, a outra mais holística reenviando o campo da formação para as suas múltiplas conexões - com o paradigma da reflexividade, com a pesquisa, com a intervenção social, entre outros; a abordagem que aqui apresento situa-se claramente na primeira destas linhas - a do debate da profissionalidade da docência;

b) a necessidade de estabelecer de forma clara conceitos estruturantes do campo, que, na minha análise serão o conhecimento e o desempenho docentes; nesta linha de análise toda a discussão da formação se encara à luz da construção e desenvolvimento do conhecimento profissional (percurso epistemológico) e do desenvolvimento da perícia ${ }^{2}$ na ação, traduzido nas competências que caracterizam o desempenho da função (percurso praxiológico) e se alimentam da constante reanálise da experiência e da permanente mobilização e construção do conhecimento.

2 Ver Carlos Marcelo, 2009, para o conceito de perícia - a competência afinada pela reflexão teorizadora da experiência que distingue o profissional expert do iniciante, na medida em que apresenta modos de análise mais abstratos e complexos. 
Subscreve-se assim a perspetiva de Rui Canário (2005) e Carlos Marcelo (2009), segundo a qual este percurso de formação do professor é mais rigorosamente caracterizado como um processo contínuo de desenvolvimento profissional, que combina a formação básica prévia ao desempenho, tal como a que resulta de outras situações formais de aquisição de conhecimento específico, com a construção e reconstrução quotidiana do saber e do agir do profissional, no interior do contexto socializador primário de um professor - a escola, esse lugar onde se aprende a ser professor, nas palavras de Canário (2005).

\section{Conhecimento profissional: saber ensinar - a competência do professor ${ }^{3}$}

Num documento apresentado em 2007 pela Comissão Europeia ao Conselho e ao Parlamento Europeus, intitulado "Para o Desenvolvimento da Qualidade da Formação de Professores,"4 enunciam-se quatro princípios para o desenvolvimento da competência e qualidade da formação de professores (Common Principles for Teacher Competences and Qualifications) de que aqui destacamos dois. Dizem eles respeito (1) à qualificação superior dos professores e correspondente expectativa de elevado nível do seu conhecimento, e (2) à sua condição de lifelong learners, vinculados pela natureza profissional do seu trabalho, ao imperativo da atualização e construção permanentes de conhecimento.

Estas duas dimensões remetem o leitor para duas questões muito simples, mas essenciais para se pensar com eficácia a melhoria da formação e do desempenho dos docentes: 1) O que faz um professor? O que define a sua ação profissional? 2) Que precisa ele de saber para desempenhar bem a função em causa?

Dito doutra forma, trata-se de estabelecer com algum rigor a função e o saber que distinguem a atividade docente, para a partir desses referentes equacionar a natureza, os requisitos e o desenvolvimento mais adequados da respetiva formação.

Importa tomar consciência de que as intervenções orientadas para a melhoria efetiva do desempenho docente e, consequentemente, para o investimento na formação de docentes, se reportam a um processo que se aproxima de uma ruptura na representação clássica do que é a docência mais do que a uma simples melhoria nos recursos e planos formativos e sua organização, como tem sido o caso de muitas reformas ocorridas na formação de professores nos nossos dois países - reforma-se sem se interrogar os pressupostos.

Partimos assim de alguns pontos prévios:

A representação social atual da atividade docente remete-a, na terminologia de Giméno Sacristán (1995) entre outros, para um estatuto de semi-profissão (por referência ao sentido sociológico do conceito de profissão, caracterizado essencialmente por função social reconhecida, autonomia de desempenho e domínio de saber próprio para a função) por um conjunto de razões muito diversas pelo peso da associação do ensino a uma atividade de natureza sobretudo prática; pela dimensão histórica da sua funcionarização associada à dependência do Estado; e ainda pela idealização/ideologização quase missionária ou militante mais que profissional, tantas vezes associada à docência. em resultado dos percursos históricos em que se desenvolveu (ROLDÃO, 2005 a)

3 Retoma-se texto da autora - ROLDÃO, 2007- adaptado a partir de comunicação na Conferência "Desenvolvimento Profissional de Professores para a Qualidade e Equidade da Aprendizagem ao Longo da Vida", realizada em Lisboa, em 27 e28 de setembro de 2007, no âmbito da Presidência Portuguesa da União Europeia.

4 Commission of the European Communities (2007). Communication from the Commission to the Council and the European Parliament: Improving the Quality of Teacher Education. 
Existe uma fragilidade do conhecimento profissional específico dos docentes, não

obstante os saberes gerais que sem dúvida dominam; essa fragilidade conduz a que se atribua a capacidade de ensinar a qualquer pessoa que conheça um assunto ou tema, como se ensinar nada requeresse de saber específico para além do conteúdo; esta vertente está em contradição com o elevado nível de qualificação académica de que o grupo é portador;

A alegada ineficácia da formação de professores resulta da ilusão da suficiência do conhecimento prévio ao exercício - inaceitável em qualquer outra profissão - paradoxalmente simétrico da ideia simplista de que é apenas na prática que se constrói e estabiliza esse conhecimento profissional.

A pouca focagem dos dispositivos de formação inicial e continuada no conhecimento profissional específico e nos instrumentos da sua construção e uso prejudica o desenvolvimento profissional futuro.

\subsection{A representação da atividade docente - que é ser professor?}

A enunciação desta questão pode parecer deslocada, na medida em que convergem na representação social da atividade docente um conjunto de naturalizações que, sob a suposta evidência, ajudam a tornar difuso o seu perfil.

Assim, a ideia mais elementar do professor como alguém que ensina alguma coisa a outros, contamina-se, por um lado, com uma noção arcaica de ensinar como apresentar/ transmitir conhecimentos formalizados, por outro, com o esbatimento da ação de ensinar face a concepções cuja matriz construtivista subscrevemos, que colocam no centro a aprendizagem do outro. No plano conceptual, contudo, estas linhas têm vindo a ser lidas dicotomicamente pela sociedade e pelos próprios docentes, acentuando ou a supremacia arcaica da prática docente como sinónima de apresentação de conteúdos, ou o esbatimento da ação docente em favor de uma alegada maior ênfase na ação do aluno.

Na verdade, do que parece tratar-se é da necessidade de reconceptualizar a própria noção de ensinar, interrogando os conceitos prévios que lhe subjazem. Como vimos desenvolvendo noutros textos o que distingue a função docente que caracteriza o professor reside sim em ensinar, mas ensinar entendido como uma atividade transitiva, traduzida na competência de fazer com que os outros aprendam (ROLDÃO, 2005 a). Contudo, tal concepção não corresponde a uma redução do protagonismo do professor, supostamente "devendo" deixar a aprendizagem entregue à responsabilidade e iniciativa do aluno, o que, tomado à letra, conduz perversamente à inevitável acentuação das diferenças sociais e culturais de partida. Pelo contrário, requer-se da sua parte um mais ativo protagonismo orientado para uma atuação muito mais sólida e diferenciada, contextual, e fundada num conhecimento profissional mais complexo.

\section{Que conhecimento distingue um professor?}

O conhecimento específico, distintivo, requerido para ensinar, no sentido que atrás explicitámos, é assim um saber eminentemente complexo e compósito. (ROLDÃO, 2007; 2007 a).

Esse conhecimento profissional inclui, como Lee Shulman tão claramente sistematizou nos anos 1980, e divulgou inicialmente em artigo de 1987 na conceituada Harvard Educational Review, alimentado por investigação prévia e subsequente (SHULMAN, 1987; 2004) o conhecimento de: 


\title{
DOI https://doi.org/10.31639/rbpfp.v13i28.545
}

\author{
- conteúdo a ensinar (content knowledge); \\ - conhecimento pedagógico-didático para a veiculação curricular de cada área de conhecimento \\ (pedagogical content knowledge $)^{5}$; \\ - processos cognitivos do aprendente (student kowledge); \\ - significados culturais associados aos conteúdos e lógicas integradoras dos elementos do currículo \\ (curriculum knowledge); \\ - influência dos contextos socioculturais dos alunos na sua percepção dos conceitos, conteúdos e \\ processos (context knowledge).
}

É a convergência integrada das dimensões anteriores em cada ato de ensinar ou ato pedagógico que torna atuante o conhecimento profissional do docente - mediante a capacidade, sustentada naquelas dimensões do conhecimento, de construção adequada de estratégias de trabalho e avaliação, com permanente regulação da aprendizagem conseguida.

O que distingue assim o conhecimento profissional que qualifica os professores para o exercício, retomando os Common Principles for Teacher Competences and Qualifications, assenta na especificidade do saber docente, e deverá por consequência informar todas as políticas e práticas de formação de professores, alimentadora de um desenvolvimento profissional continuado, à semelhança do que se passa em outras profissões, como o médico ou o arquiteto. Tal especificidade, na esteira da classificação supra, resulta da sustentação que esse saber oferece para (1) desempenhar adequadamente a ação de ensinar, (2) ser capaz de pensar e teorizar essa ação, e (3) dominar os instrumentos da sua efetiva e permanente melhoria. Importa assim desconstruir a ideia do professor como apenas um prático dispensado de teorizar, tanto quanto a do professor como um apresentador ex cathedra de conhecimento formalizado.

\section{Teoria e prática - o interminável desencontro?}

A redução da prática de ensino à ideia de atividade prática, na leitura corrente de professores e futuros professores expressa em inúmeras investigações das últimas décadas ROLDAO, 2006; 2011; ANDRÉ, 2010; 2010 a), conduz a uma cultura profissional que se vem manifestando como largamente resistente à chamada teorização, à conceptualização do agir docente, à sua desmontagem crítica, e analítica, com prejuízo da sua autonomia e da sua competência para reorientar a ação e melhorar os resultados. .

O contributo de Donald Schön, na década de 1980 e seguintes, para a teorização do conhecimento profissional em geral - não apenas no caso dos docentes, mas em diversas profissões como músico, ou arquiteto, que no seu trabalho analisou em detalhe - clarifica a indissociabilidade do conhecimento profissional relativamente à prática profissional que Ihe corresponde (SCHÖN, 1987). No essencial, Schön abandona a ideia aplicacionista muitas vezes associada à expressão "relação teoria/prática" - assumindo o conhecimento teórico como supostamente prévio e posteriormente "aplicável" à prática - para salientar a prática profissional como elemento-chave da própria produção de conhecimento, mediante dispositivos de reflexão/construção adequados, associados à natureza singular e imprevisível do agir profissional e das questões que dele emergem. 
Trata-se assim de abandonar a visão do professor como um "prático" - alguém que dá aulas - substituindo-a pela de prático reflexivo, na perspetiva de Schön; isso implica por um lado o reconhecimento da centralidade da prática profissional nos seus contextos reais, mas olhada como alimentadora, geradora e integradora de saber profissional próprio, por sua vez alimentado quer por saberes formalizados previamente apropriados e constantemente renovados, reconstruídos e ampliados face às situações ( os "casos" na terminologia feliz da profissão médica), quer pelo questionamento analítico-investigativo (reflexivo, na terminologia de Schön) das circunstâncias, problemas, sucessos e insucessos da ação desenvolvida.

A atribuição da supremacia do "prático" na docência tem contribuído para desprofissionalizar a docência, que, pela sua natureza e finalidade, se situará antes no lugar de uma atividade que é uma prática, mas cujos agentes sabem interrogar, teorizar e melhorar (ROLDÃO, 2007).

Os termos reflexividade e prático reflexivo têm sido objeto de uma banalização no léxico dos professores e das escolas, e até da administração e das instituições formadoras, que descaracteriza frequentemente a ideia-chave desta aproximação - reflexividade entendida como a teorização e a fundamentação rigorosa da ação profissional a partir do questionamento contextualizado e teorizado da sua prática.

Para que a reflexividade implique construção de conhecimento sustentado, terá que se traduzir em dispositivos analítico-investigativos, orientados para a formulação de hipóteses explicativas e sua fundamentação e verificação. Tal prática reflexiva pressupõe ainda a análise e a discussão entre os pares face às situações de ensino e aprendizagem vivenciadas, e a produção de interpretações fundamentadas em saber, susceptíveis de ser reinvestidas na ação.

Só a reflexividade assim entendida pode garantir a ruptura com a circularidade improdutiva das inúmeras discussões e trocas de opiniões realizadas no quotidiano dos professores e desesperantemente incapazes de produzir saltos qualitativos nas suas práticas, não obstante o investimento, o interesse, o empenhamento e genuíno esforço.

A prática reflexiva requer pois:

(1) o recurso a conhecimento teórico e prático prévios,

(2) a teorização problematizadora da situação prática em apreço, e

(3) a produção de conhecimento susceptível de ser comunicado a outros, e mobilizado noutras situações.

Esta constatação implica o olhar atento sobre o lugar da pesquisa na formação inicial de professores e também no seu desenvolvimento profissional no longo termo, encarando como um imperativo da qualidade o seu reforço, bem como a promoção de algumas iniciativas políticas e projetos de intervenção, quer públicas quer das instituições formadoras - como já vem sendo tentado em vários sistemas incluindo o brasileiro alimentadoras do continuum da atividade profissional docente ao longo de toda a carreira.

\section{Universidade e escolas - para reduzir o fosso que as separa}

A cultura e práticas das universidades e outras instituições de ensino superior onde se desenvolve a formação inicial de professores, e as escolas, seus contextos de trabalho, refletem culturas naturalmente diversas nas suas histórias e constituição. Nas instituições formadoras privilegia-se, de um modo geral a pesquisa e a 
construção de conhecimento, nas escolas valoriza-se a ação e seus resultados. Para superar esta diferença histórica, na formação de profissões como os professores ou os médicos que agem na sociedade mas só o podem fazer com sucesso se respaldados num sólido conhecimento, importa modificar as políticas de formação.

Projetos de interligação da formação de base à prática do futuro profissional têm sido levadas a cabo em Portugal e no Brasil mediante projetos de investigação com ligação as escolas em que os formandos irão trabalhar (ROLDÃO et al. 2005), numa perspetiva de reflexão e pesquisa sobre a prática, distanciada de umam mera lógica aplicacionista.

Decorrente da participação da autora supra referida Conferência da Comissão Europeia de Lisboa em 2007, resultaram algumas reflexões originadas pelas Propostas de atuação para a formação de professores no quadro das políticas dos Estados Membros da União Europeia 6 configurando linhas sugeridas para a ação que permanecem atuais e aqui se retomam (ROLDÃO, 2007).

Tomando como referência a noção de conhecimento profissional docente assente na função e competência de ensinar que distingue o professor como profissional, e à luz da Recomendação sobre Qualidade da Formação de Professores para as políticas dos Estados Membros da UE, parece possível identificar algumas linhas orientadoras para a melhoria da qualidade da formação dos professores e consequente impacto na melhoria das aprendizagens dos alunos:

\section{a) Assunção da formação de professores como um processo contínuo de desenvolvimento profissional}

Esta perspetiva pressupõe romper com a lógica até agora dominante em duas vertentes: por um lado, pela assunção clara da natureza profissional da atividade docente e do défice atual relativamente a este estatuto; por outro, implica conceptualizar a formação inicial e contínua como um todo, estabelecendo para isso os necessários dispositivos organizacionais, nomeadamente a responsabilização das Universidades e outras instituições de formação superiores pelos vários níveis e momentos da formação de professores, regulados pelos referenciais europeus.

\section{b). Estabelecimento continuado de parcerias de formação entre instituições formadoras e escolas}

Reconhece-se a necessidade da criação de parcerias formativas entre as Universidades e Escolas Superiores e as escolas e professores no terreno, criando redes de formação em torno de cada instituição formadora, cujos recursos se podem constituir em suporte do trabalho docente nessas mesmas escolas. Isso pressupõe a inclusão explícita deste apoio às escolas e agrupamentos na missão das Universidades e Escolas Superiores, com a respetiva avaliação reguladora de resultados e procedimentos.

c) Estabelecimento da dimensão da formação dos docentes como um dos elementos da organização das escolas e da sua avaliação

Nesta vertente, importará considerar que a cultura existente, em Portugal e em alguns outros países de administração mais centralista da União Europeia, não tem esta tradição. As medidas para a incentivar não podem assim centrar-se na normatividade, nem na uniformidade prescrita de procedimentos, mas sim na 
regulação e no incentivo a práticas de formação concebidas e geridas pelas escolas, em parceria com as instituições de formação, para melhorar a sua ação, refletidas na melhoria do seu desempenho e da aprendizagem dos seus alunos.

d) Estabelecimento da centralidade da prática docente supervisionada, em todos os momentos e percursos de formação

Na linha que vimos defendendo, o trabalho de formação de qualquer profissional deverá ter como eixo estruturante a problematização e a vivência da prática profissional e seus contextos - veja-se o paralelismo com a formação médica por exemplo. Essa linha, já ensaiada e investigada em numerosas situações bem-sucedidas, deverá também assumir centralidade na organização de qualquer formação de docentes.

Tal não significa uma redução da dimensão científica (pelo contrário, parece necessário reforçar a sua solidez) nem das dimensões pedagógico-didáticas que integram o saber profissional (também elas necessitando de idêntica valorização e aprofundamento permanentes). Significa sim uma reconceptualização da formação, integrando numa política global os níveis da formação inicial e da formação continuada nos contextos de trabalho, no sentido de articular a apropriação de todos os campos de conhecimento com uma adequada mobilização e uso de saber em situações de ensino concretas, apoiadas e supervisionadas.

Trata-se assim de instituir a supervisão como um dispositivo de trabalho regular nas escolas, dimensão que é hoje, no sistema português e contrariamente aos seus parceiros europeus, um espaço vazio no percurso profissional dos professores.

\section{Estabelecimento da investigação como componente essencial da formação e da ação pro- fissional}

Esta questão, que figurava também nas recomendações da União Europeia a que nos referimios acima, tem sido controversa no mundo académico, ciosos que são os investigadores e académicos da delimitação do seu território, nesta como em outras áreas de saber. Parece, contudo, consensual a necessidade e valia do apetrechamento e capacitação dos docentes com saber e domínio de instrumentos conceptuais e técnicos de investigação, que lhes permitam tornar efetiva e rigorosa a sua reflexão analítica sobre a ação de ensino que desenvolvem e permanecer, ao longo da sua vida profissional, utilizadores competentes da investigação produzida noutras sedes.

O conceito de professor pesquisador, inicialmente cunhado por Lawrence Stenhouse (1991) deu origem a numerosas tentativas que esbarram regularmente na difícil incorporação da pesquisa nas lógicas e condições de trabalho das escolas, orientadas por outras finalidades sociais prementes. Contudo, o ganho da harmonização da pesquisa com a prática é imenso, requerendo contudo um ajuste que por maioria de razão deve ser trabalhado na formação inicial, sustentando a formação para a análise da prática profissional ao longo da carreira e nos contextos respetivos.

Em jeito de síntese, as reflexões e pesquisas no campo que nos ocupa - que alimentaram as muitas interações que tive o privilégio de partilhar com Marli André ao longo dos anos - apontam para a necessidade de construção de uma outra cultura profissional: assente na redefinição conceptual e social da função docente num tempo de educação como um direito de todos, a que urge responder com professores que se constroem, com base na especificidade e complexidade do seu saber, não apenas no tempo da formação inicial mas num continuum, que se alicerce nesse ponto inicial mas se amplie num permanente desenvolvimento profissional ao longo da vida, suportado pela pesquisa e pela análise reguladora do desempenho. 


\section{Referências bibliográficas}

ANDRÉ, Marli. Etnografia da prática escolar. Papirus Editora, 1995.

ANDRÉ, Marli. A pesquisa sobre formação de professores: contribuições à delimitação do campo. In: DALBEN, Ângela I.L.F. et al. Didática: convergências e tensões no campo da formação e do trabalho docente. Belo Horizonte: Autêntica, 2010. p. 273-283.

ANDRÉ, Marli. A produção acadêmica sobre formação de professores: um estudo comparativo das dissertações e teses defendidas nos anos 1990 e 2000. Formação Docente - Revista Brasileira de Pesquisa sobre Formação Docente, v. 1, n. 1, p. 41-56, ago./dez. 2009. Disponível em: . Acesso em: 5 abr. 2010a

CANÁRIO, Rui. O que é a Escola? Um "Olhar" Sociológico. Porto: Porto Editora, 2005.

GIMENO SACRISTÁN, José. Consciência e ação sobre a prática como libertação profissional dos professores. In: António Nóvoa (Org.) Profissão professor. pp. 63-92. Porto: Porto Editora. 1995.

MARCELO GARCIA, Carlos. Desenvolvimento Profissional: passado e futuro. Sísifo - Revista das Ciências da Educação, n. 08, p. 7-22, jan./abr. 2009.

ROLDÃO, Maria do Céu (coord.) HAMIDO,G. e GALVEIAS, F. Os professores e o desenvolvimento da sua identidade profissional. O que nos diz a investigação. Subprojecto desenvolvido no âmbito do Projecto de Investigação Supervisão e Desenvolvimento da Identidade Profissional -Estudo sobre a influência da supervisão e dos contextos nas transições ecológicas de construção e desenvolvimento profissional. (coord. Isabel Alarcão). Aveiro: CIDTFF, Centro de Investigação em Didáctica e Tecnologia na Formação de Formadores, Universidade de Aveiro (Financiado pela Fundação para a Ciência e a Tecnologia). 2005. Texto não publicado.

ROLDÃO, Maria do Céu (2005 a). Profissionalidade docente em análise - especificidades dos ensinos superior e não superior. Revista NUANCES, UNESP (Universidade do Estado de S.Paulo )., ano XI, n 13, Jan-Dez 2005, 108-126, 2005a.

ROLDÃO, Maria do Céu, NETO-MENDES, A., Costa, J.A. \& ALONSO, L. Organização do trabalho docente: uma década em análise (1996-2005). Investigar em Educação n. ${ }^{\circ} 5$ - Revista da Sociedade Portuguesa de Ciências da Educação, 17-148, 2006.

ROLDÃO, Maria do Céu. A formação de professores como objecto de pesquisa - contributos para a construção do campo de estudo a partir de pesquisas portuguesas. Revista Eletrónica de Educação da UFSCar, São Carlos, Brasil. 2007. www.portaldosprofessores.ufscar.br

ROLDÃO, Maria do Céu. Função docente: natureza e construção do conhecimento profissional. Revista Brasileira de Educação, Jan-Abril, n. ${ }^{\circ}$ 34, 94-103, 2007 a.

ROLDÃO, Maria do Céu. Formação de professores baseada na investigação e prática reflexiva. In Actas da Conferência "Desenvolvimento Profissional de Professores para a Qualidade e Equidade da Aprendizagem ao Longo da Vida", Lisboa, 2008, no âmbito da Presidência Portuguesa da União Europeia. 
ROLDAO, Maria do Céu. Formação de professores na investigação portuguesa - um olhar sobre a função do professor e o conhecimento profissional. Revista Portuguesa de Investigação Educacional, 10/2011 ,135 $-150,2011$.

SCHÖN, Donald. Educating the Reflective Practitioner. How Professionals think iin Action. London: Temple Smith, 1987.

SHULMAN, Lee. Knowledge and teaching: foundations of the new reform. Harvard Educational Review, 57, 4-14, 1987.

SHULMAN, Lee \& SHULMAN, Judith. How and what teachers learn: a shifting perspective. Journal of Curriculum Studies, v. 36, nº 2, March-April, 257-271, 2004.

STENHOUSE, Lawrence. Investigación y Desarrollo del Curriculum (1 $1^{\mathrm{a}}$ ed. 1981). Madrid. Ediciones Morata, 1991. 
